\title{
ADSORÇÃO DE AZUL DE METILENO DE SOLUÇÃO AQUOSA COM UTILIZAÇÃO DE PÓ DE SERRAGEM DE MDF E MADEIRITE E CARVÃO ATIVADO GRANULAR
}

\author{
G. VALCARENGHI ${ }^{1}$, L.F.P. RIBEIRO ${ }^{1}$, J. L. B. TREVIZANI ${ }^{2}$, L. M. LUNARDI ${ }^{3}$, K. Q. De \\ CARVALHO $^{1}$, F. H. PASSIG ${ }^{4}$, F.B. FREIRE ${ }^{2}$, T. M. CASTRO ${ }^{3}$, C. KREUTZ ${ }^{3}$ \\ ${ }^{1}$ Universidade Tecnológica Federal do Paraná, Departamento Acadêmico de Construção Civil \\ câmpus Curitiba (DACOC/UTFPR). \\ ${ }^{2}$ Universidade Tecnológica Federal do Paraná, Programa de Pós-Graduação em Engenharia Civil \\ câmpus Curitiba (PPGEC/UTFPR). \\ ${ }^{3}$ Universidade Tecnológica Federal do Paraná, Departamento Acadêmico de Ambiental câmpus \\ Campo Mourão (DAAMB/UTFPR). \\ ${ }^{4}$ Universidade Tecnológica Federal do Paraná, Programa de Pós-Graduação em Ciência e Tecnologia \\ Ambiental (PPGCTA/UTFPR). \\ E-mail para contato: jlbtrevizani@gmail.com
}

\begin{abstract}
RESUMO - Um dos principais problemas da indústria têxtil é a remoção da concentração de corantes contida em seus efluentes. Dentre os métodos de remoção de cor, a adsorção tem sido estudada e aplicada com diversos materiais alternativos. O objetivo deste trabalho foi avaliar a utilização do pó de serragem de MDF e de madeirite como material adsorvente na remoção do corante azul de metileno $(0,15 \mathrm{~g} / \mathrm{L})$ como alternativa para o carvão ativado granular. Ensaios foram conduzidos com variação de massa de adsorvente $(1 \mathrm{~g}, 2 \mathrm{~g}, 3 \mathrm{~g}, 4 \mathrm{~g}, 5 \mathrm{~g}$ e $6 \mathrm{~g})$ e pH $(5,5,6,5,7,5,8,5,9,5$ e 10,5). Os ensaios de adsorção indicaram melhores eficiências de remoção de corante de 98,2\% (MDF), 97,9\% (madeirite) e 100\% (carvão ativado granular) com massa de adsorvente de $6 \mathrm{~g}$ e de 97,7\% (MDF), 98,2\% (madeirite) e 100\% (carvão ativado granular) para $\mathrm{pH}$ de 7,5. Foi possível concluir que o pó de serragem de MDF e de madeirite são eficientes na remoção de cor pelo processo de adsorção em solução aquosa com azul de metileno.
\end{abstract}

\section{INTRODUÇÃO}

Os efluentes têxteis são caracterizados por serem altamente coloridos, devido à presença de corantes que não se fixam às fibras durante o processo de tingimento gerando grande quantidade de resíduos (KUNZ, ZAMORA, MORAES, DURÁN; 2002). As principais técnicas disponíveis para descoloração de efluentes têxteis envolvem principalmente processos de adsorção, precipitação, degradação química, eletroquímica, fotoquímica e biodegradação (GUARATINI; ZANONI, 1999).

O processo de adsorção não tem sido utilizado extensivamente no tratamento de efluentes 
industriais, mas a demanda por melhor qualidade neste tratamento, inclusive na redução da toxicidade, tem levado ao estudo do processo de adsorção com carvão ativado (METCALF; EDDY, 2004).

O carvão ativado é o adsorvente mais utilizado devido à sua excelente eficiência na remoção de cor. Garg et al. (2004) observaram remoção de 100\% dos corantes e metais pesados ao utilizarem este adsorvente. Porém, seu uso é restrito devido ao seu custo de cerca de $\mathrm{R} \$ 50,00 / \mathrm{Kg}$ de carvão (Ecocarbo, 2012). Além disso, o carvão possui superfície eletricamente positiva, o que dificulta a adsorção de corantes catiônicos como o azul de metileno. Devido a isso, outros materiais de menor custo vêm sendo estudados.

O pó de serragem, encontrado em madeireiras, marcenarias e obras de construção civil, apresentou ótimas características adsorventes nas pesquisas de Garg et al. (2004), Antunes et al. (2010) e de Ikeno (2013), sendo interessante o uso deste resíduo, como alternativa barata e ecológica, para remoção de corantes de efluentes têxteis. Dentro deste contexto, no presente trabalho é apresentado um estudo sobre o uso do pó de serragem como material alternativo, econômico e sustentável à remoção do corante azul de metileno por adsorção.

\section{MATERIAL E MÉTODOS}

\subsection{Caracterização do Material Adsorvente}

Para determinar as características físico-químicas foram feitas determinações em triplicata do pH (ASTM D 3838-80/1990), densidade aparente (NBR 12076/1991), densidade específica (NBR NM 23/2001), teor de umidade (ASTM D 2867/2004) e granulometria (NBR NM 248/2003) das amostras de pó de serragem de MDF e de madeirite.

\subsection{Ensaios de Adsorção}

Os ensaios de adsorção foram realizados em duplicata e para simular a concentração de corante do efluente têxtil, foi utilizada solução com corante azul de metileno $\left(\mathrm{C}_{16} \mathrm{H}_{18} \mathrm{CIN}_{3} \mathrm{~S}\right)$ em pó da marca Quemis $\left(85 \%\right.$ de conteúdo de corante, fórmula química $=\mathrm{C}_{16} \mathrm{H}_{18} \mathrm{CIN}_{3} \mathrm{~S} \cdot \mathrm{XH}_{2} \mathrm{O} ; \mathrm{FW}=319,86$; natureza $=$ azul básico) na concentração de $0,15 \mathrm{~g} / \mathrm{L}$.

A solução aquosa com corante azul de metileno e a massa de cada material adsorvente foram colocadas no equipamento de Jar Test da marca PoliControl, modelo FlocControl II em rotação de $120 \mathrm{rpm}$ a temperatura ambiente durante $150 \mathrm{~min}$.

A análise do efeito da variação da massa foi feita com amostras de 1, 2, 3, 4, 5 e 6 g de cada material adsorvente. Para massa de $6 \mathrm{~g}$ de cada adsorvente variou-se o $\mathrm{pH}$ em 5,5, 6,5, 7,5, 8,5, 9,5 e 10,5 para analisar o efeito da variação do $\mathrm{pH}$ na remoção do corante azul de metileno.

Alíquotas de $5 \mathrm{~mL}$ de amostra foram coletadas de cada jarro, em duplicata, em intervalos de tempo de 15, 30, 60, 90, 120 e 150 minutos. Após a coleta, foi feita leitura da absorbância das 
amostras no espectrofotômetro Femto, modelo 600 Plus com comprimento de onda de $396 \mathrm{~nm}$, previamente calibrado com água.

2.2.1.Eficiência da Remoção de Corante: Para avaliar a eficiência da remoção de corante foi utilizada a curva de calibração do corante azul de metileno para o comprimento de onda de $396 \mathrm{~nm}$. $\mathrm{Na}$ Figura 1 é apresentado o ajuste linear da curva de calibração que relaciona a concentração do corante azul de metileno e a absorbância lida no espectrofotômetro e a estrutura química do corante azul de metileno.

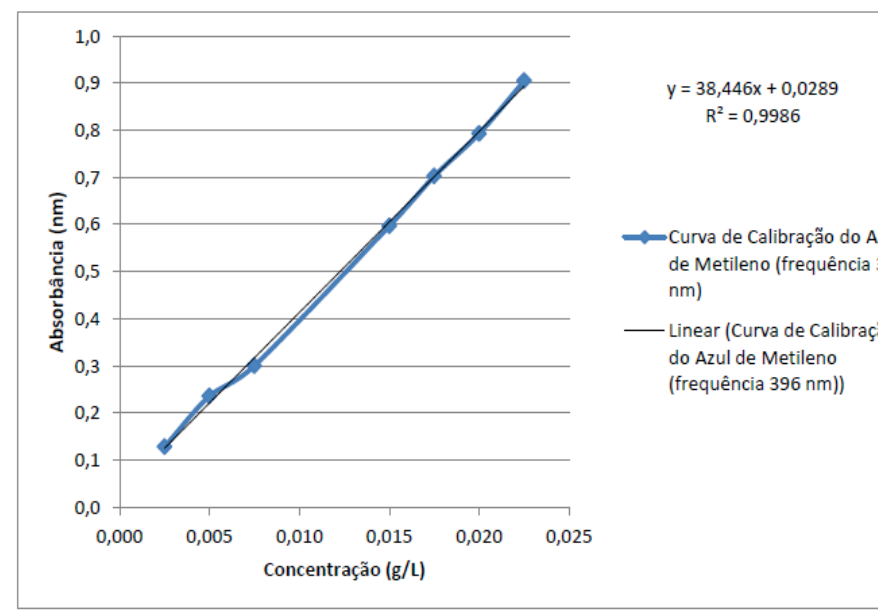

(a)

Figura 1 - Curva de calibração do corante azul de metileno (396 nm)

2.2.2. Cinética de Adsorção: A constante cinética de adsorção de pseudo-primeira ordem de Lagergren foi avaliada com as massas de 1 a 6 g de adsorvente em contato com 1 L da solução de azul de metileno por 150 minutos em $\mathrm{pH}$ 7,5. Os resultados da concentração do corante foram aplicados no modelo cinético de pseudo-primeira ordem de Lagergren de acordo com a Equação 1.

$$
\log (q e-q t)=\log q e-\frac{k 1}{2,203} t
$$

Em que: $q \mathrm{t}=$ Capacidade de adsorção em um tempo $\mathrm{t}(\mathrm{mg} / \mathrm{g})$; qe = Capacidade de adsorção no equilíbrio (mg/g); k1 = Constante cinética de pseudo-primeira ordem de adsorção (1/min).

Os mesmos dados foram utilizados no ajuste do modelo cinético de pseudo-segunda ordem de Lagergren, de acordo com a Equação 2.

$$
\frac{t}{q t}=\frac{1}{k 2 \cdot q \theta^{2}}+\frac{1}{q \theta} \cdot t
$$

Em que: k2 = Constante cinética de pseudo-segunda ordem de adsorção (mg/g.min). 


\section{RESULTADOS E DISCUSSÕES}

\subsection{Caracterização dos Adsorventes}

Os resultados da caracterização físico-química do pó de serragem de MDF e de madeirite e do carvão ativado granular (CAG) foram obtidos pela média dos resultados dos ensaios (Tabela 2).

Tabela 2 - Características físicas do carvão ativado e do pó de serragem de MDF e madeirite

\begin{tabular}{|c|c|c|c|}
\hline Característica & Carvão ativado granular & MDF & Madeirite \\
\hline $\mathbf{p H}$ & $6,70 \pm 0,08$ & $4,92 \pm 0,07$ & $7,08 \pm 0,02$ \\
\hline Teor de umidade (\%) & $9,0 \pm 0,01$ & $12,7 \pm 3,56$ & $27,2 \pm 0,53$ \\
\hline Densidade aparente $\mathbf{( g / m L )}$ & $0,63 \pm 0,01$ & $0,226 \pm 0,01$ & $0,152 \pm 0,001$ \\
\hline Densidade específica $\mathbf{( g / m L )}$ & - & $1,425 \pm 0,05$ & $1,401 \pm 0,03$ \\
\hline
\end{tabular}

Os valores do $\mathrm{pH}$ indicam acidez do CAG e do MDF. Resultados similar foram obtidos por Garg et al. (2004) de 6,5 a 7,5 para CAG, Ikeno (2013) de 6,24 $\pm 0,10$ para CAG e 4,1 $\pm 0,06$ para pó de serragem e Antunes et al. (2012) de 4,4 para serragem da madeira.

Pelo teor de umidade, foi possível notar que o MDF e o madeirite apresentaram maior capacidade de reter água do que o CAG, ou seja, são materiais mais porosos e suportam maior quantidade de líquido. Os valores obtidos neste trabalho foram superiores aos observados de $3,82 \% \mathrm{e}$ $3 \%$ para pó de serragem de Dalbergia sissoo tratada com ácido sulfúrico de 1\% e para carvão ativado granular (GARG et al., 2004) e de 6,24\% para carvão ativado granular (LOUREIRO, 2012).

\subsection{Variação da Massa de Adsorvente}

Independente do tipo de adsorvente, os melhores resultados de remoção do corante foram obtidos com o aumento da massa de adsorvente, sendo as maiores remoções observadas com massa de $6 \mathrm{~g}$ de adsorvente no final de 150 min para serragem de $\operatorname{MDF}(98,2 \%)$, de madeirite $(97,9 \%)$ e para o carvão ativado (aproximadamente 100\%).

Geçgel et al. (2012) utilizaram o mesmo corante para adsorção com carvão ativado de casca de ervilha e obtiveram aumento de $33,58 \%$ para $99,41 \%$ de remoção em função do aumento de massa de adsorvente de 0,05 para $0,2 \mathrm{~g}$. Ikeno (2013) obteve $81,6 \%$ de remoção do AM nos ensaios com a maior massa $(1,0 \mathrm{~g})$ a $30^{\circ} \mathrm{C}$.

\subsection{Variação do pH}

A variação do $\mathrm{pH}$ da amostra foi realizada para investigar a influência na remoção do $\mathrm{AM}$ nos ensaios. Na Figura 2 são apresentadas as variações de remoção de corante azul de metileno em função do tempo e do $\mathrm{pH}$, com massa de $6 \mathrm{~g}$ para pó de serragem de MDF e de madeirite e de carvão ativado 
granular. Optou-se por iniciar o eixo x dos gráficos em 95\%, pois as curvas de eficiência de remoção são similares, e ao adotar o referido eixo iniciando em zero, não seria possível observar a diferença entre as eficiências de remoção em função da maior escala.

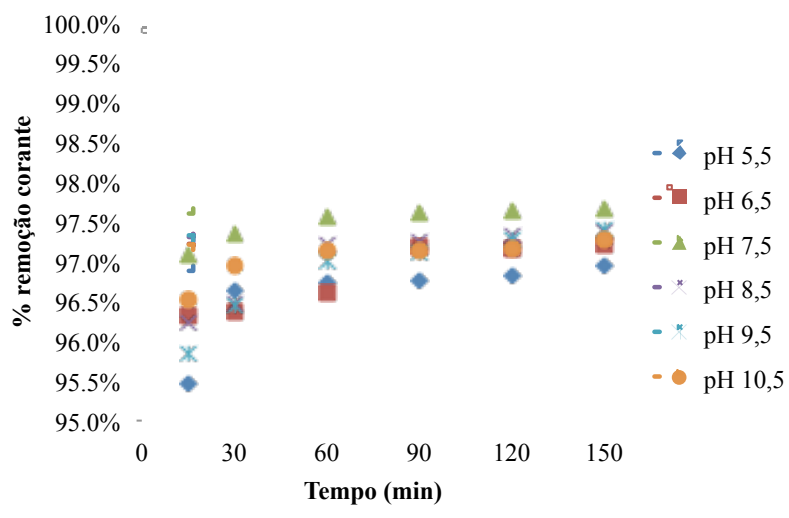

(a)

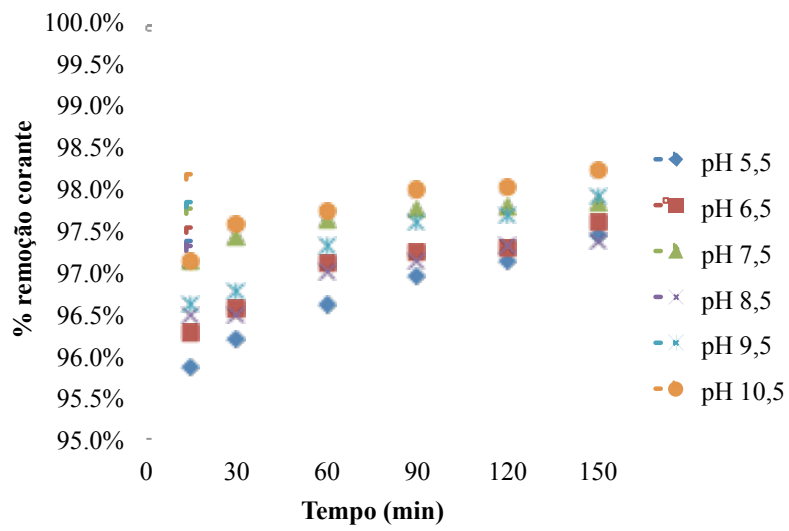

(b)

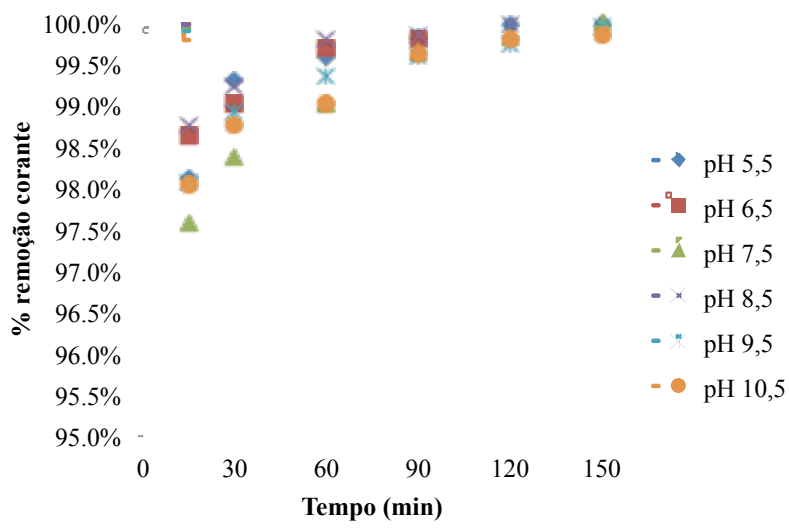

c)

Figura 2 - Eficiência da remoção do corante pelo tempo para variação de $\mathrm{pH}$ para pó de serragem de MDF (a); pó de serragem de madeirite (b); carvão ativado granular (c). 
O melhor resultado de remoção do corante de 97,7\% para a serragem de MDF foi obtido com pH 7,5 aos 150 min (Figura 2). Para o pó de serragem de madeirite, o melhor resultado de 98,2\% foi obtido com pH 10,5 aos 150 min. Com o carvão ativado granular, foi verificado $100 \%$ de remoção do corante aos 150 minutos com pH 7,5 mantendo eficiência superior aos demais durante todo o tempo.

Garg et al. (2004) utilizaram o corante azul de metileno e obtiveram melhor eficiência em pH 7,0 para a serragem de Indian Rosewood e para carvão ativado. Matos et al. (2011) obtiveram melhor remoção com $\mathrm{pH}$ 9,0 no processo de adsorção do corante verde brilhante sobre ligno-celulose do talo de açaí.

Ikeno (2013) verificou maiores eficiências de adsorção de 78,9\%, 79,5\% e 78,7\% em 90, 135 e 150 min no $\mathrm{pH} 7,5$, respectivamente, resultando médias de 73,5\%; 72,7\% no pH 6,5; 62,09\% no pH 8,5 e $56,1 \%$ no $\mathrm{pH} 5,5$. Assim, é possível notar que a influência do $\mathrm{pH}$ depende do tipo de material adsorvente e do corante utilizado.

É importante ressaltar que a reação do corante azul de metileno considerado básico com adsorventes ácidos torna-o susceptível a maior interação, principalmente em sua superfície, quando a adsorção do complexo doador-receptor ocorre principalmente na superfície dos meso e microporos (TERZYK, 2003).

\subsection{Cinética de Adsorção}

Os resultados obtidos para as constantes cinéticas de pseudo-primeira ordem (k1) de Lagergren e de pseudo-segunda ordem $(\mathrm{k} 2)$ e seus respectivos coeficientes de correlação $\left(\mathrm{R}^{2}\right)$ são apresentados na Tabela 3 .

Tabela 3 - Parâmetros dos modelos cinéticos de pseudo-primeira ordem e pseudo-segunda ordem para remoção do azul de metileno.

\begin{tabular}{|c|c|c|c|c|c|}
\hline \multirow{2}{*}{ Adsorvente } & Massa & k1 & \multirow{2}{*}{$\mathbf{R}^{2}$} & k2 & \multirow{2}{*}{$\mathbf{R}^{2}$} \\
\hline & (g) & $(1 / \min )$ & & (mg/g.min) & \\
\hline \multirow{6}{*}{ MDF } & $1 \mathrm{~g}$ & 0,0316 & 0,4774 & 0,0366 & 1,0000 \\
\hline & $2 \mathrm{~g}$ & 0,0500 & 0,7257 & 0,0514 & 1,0000 \\
\hline & $3 \mathrm{~g}$ & 0,0474 & 0,7052 & 0,0462 & 1,0000 \\
\hline & $4 \mathrm{~g}$ & 0,0311 & 0,4057 & 0,0420 & 1,0000 \\
\hline & $5 \mathrm{~g}$ & 0,0350 & 0,4870 & 0,0578 & 1,0000 \\
\hline & $6 \mathrm{~g}$ & 0,0332 & 0,5241 & 0,0330 & 1,0000 \\
\hline \multirow{6}{*}{ Madeirite } & $1 \mathrm{~g}$ & 0,0263 & 0,3949 & 0,0476 & 1,0000 \\
\hline & $2 \mathrm{~g}$ & 0,0387 & 0,5431 & 0,0680 & 1,0000 \\
\hline & $3 \mathrm{~g}$ & 0,0449 & 0,6590 & 0,0529 & 1,0000 \\
\hline & $4 \mathrm{~g}$ & 0,0484 & 0,7121 & 0,0514 & 1,0000 \\
\hline & $5 \mathrm{~g}$ & 0,0470 & 0,6644 & 0,0578 & 1,0000 \\
\hline & $6 \mathrm{~g}$ & 0,0408 & 0,5799 & 0,0578 & 1,0000 \\
\hline
\end{tabular}




\begin{tabular}{|c|c|c|c|c|c|}
\hline \multirow{4}{*}{$\begin{array}{c}\text { Carvão ativado } \\
\text { granular }\end{array}$} & $1 \mathrm{~g}$ & 0,0263 & 0,3970 & 0,0476 & 1,0000 \\
\cline { 2 - 6 } & $2 \mathrm{~g}$ & 0,0332 & 0,5677 & 0,0231 & 1,0000 \\
\cline { 2 - 6 } & $3 \mathrm{~g}$ & 0,0442 & 0,7627 & 0,0185 & 1,0000 \\
\cline { 2 - 6 } & $5 \mathrm{~g}$ & 0,0401 & 0,7294 & 0,0160 & 1,0000 \\
\cline { 2 - 6 } & $5 \mathrm{~g}$ & 0,0447 & 0,7849 & 0,0578 & 1,0000 \\
\cline { 2 - 6 } & $6 \mathrm{~g}$ & 0,0412 & 0,7411 & 0,0187 & 1,0000 \\
\hline
\end{tabular}

Na Tabela 4 é possível notar que o melhor ajuste dos dados experimentais foi o do modelo de pseudo-segunda ordem de Lagergren para velocidade da adsorção, com valores médios de k2 de $0,0445,0,0559$ e 0,0303 para pó de serragem de MDF, madeirite e carvão ativado, respectivamente.

Ikeno (2013) encontrou valor médio de $0,036 \mathrm{~L} / \mathrm{min}$ para o valor de $\mathrm{k} 1$ no ajuste de pseudoprimeira ordem, com valor de $\mathrm{R}^{2}$ médio de 0,912 , valor bem próximo à 1,0 , similar ao valor encontrado neste trabalho.

\section{CONCLUSÃO}

Os ensaios de adsorção demonstraram a eficiência do pó de serragem de MDF e madeirite em comparação com o carvão ativado, adsorvente mais utilizado atualmente. A eficiência do carvão ativado para $6 \mathrm{~g}$ de adsorvente e $\mathrm{pH}$ de 7,5 (100\%) se mostrou maior do que os de pó de serragem de MDF $(98,2 \%)$ e de pó de serragem de madeirite $(97,9 \%)$.

O ajuste cinético de adsorção pelo modelo de pseudo-segunda ordem de Lagergren foi melhor no pó de serragem de madeirite, com maior velocidade na remoção do corante azul de metileno, seguido do pó de serragem de MDF e do carvão ativado granular.

Pode-se concluir que a adsorção do corante azul de metileno em solução aquosa com o pó de serragem de MDF e de madeirite é viável, considerando que é um resíduo facilmente encontrado, com menor custo em comparação ao carvão ativado.

\section{REFERENCIAS}

AMERICAN SOCIETY FOR TESTING AND MATERIALS. ASTM D 2867-04: Standard Test Method for Moisture in activated Carbon. 2004.

. ASTM D 3838-80: Standard Test Method for pH of Activated Carbon. 1999

ANTUNES, M.L.P.; CAMARGO, S.R.G. de; JESUS, C.P. de; RUSSO, A.C. Estudo da utilização de Serragem de Madeira como Adsorvente Para Tratamento de Efluentes Têxteis. Estudos Ambientais, v. 12, n. 12, p. 6-14, 2010. 
ASSOCIAÇÃO BRASILEIRA DE NORMAS TÉCNICAS. NBR 9800: Critérios para lançamento de efluentes líquidos industriais no sistema coletor público de esgoto sanitário. Rio de Janeiro, 1987.

. NBR 12076: Carvão Ativado Pulverizado - Determinação da massa específica aparente. Rio de Janeiro, 1991.

NBR NM 23: Cimento Portland e outros materiais em pó - Determinação da massa específica. Rio de Janeiro, 2001.

$\overline{2001 .}$

. NBR NM 248: Agregado - Determinação da composição granulométrica. Rio de Janeiro,

GARG, V. K.; MOIRANGTHEM, A.; RAKESH, K.; RENUKA, G. Basic dye (methylene blue) removal from simulated wastewater by adsorption using Indian Rosewood sawdust: a timber industry waste. Dyes and pigments, v. 63, n. 3, p. 243-250, 2004.

GEÇGEL, U.; OZCAN, G.; GURPINAR, G.C. Removal of Methylene Blue from Aqueous Solution by Activated Carbon Prepared from Pea Shells (Pisum sativum). Journal of Chemistry, v. 20, n. 13, p. 1-9, 2012.

GUARATINI, C.C. I.; ZANONI, M.V.B. Corantes Têxteis. Química Nova, v. 23, p 71-78, 2000.

IKENO, D.S. Remoção de azul de metileno de efluente têxtil sintético por adsorção usando pó de serragem do gênero Pinus sp. 2013. 59 f. Monografia (Engenharia Ambiental) - Universidade Tecnológica Federal do Paraná. Campo Mourão, 2013.

LOUREIRO, L.F. Avaliação da Adsorção do Herbicida 2,4-D em Carvão Ativado em Pó e Granular por meio de Análise de Isoterma de Adsorção utilizando Diferentes Qualidade de Água. 2012. 80f. Dissertação (Mestrado em Engenharia Ambiental) - Universidade Federal do Espírito Santo. Vitória, 2012.

MATOS, N.; RODRIGUES, H.; ARAÚJO JR., E.; MOURA, J.; SILVA FILHO, E.; LIMA, C.; ALENCAR, W. Estudo do pH no processo de remoção do corante Verde Brilhante sobre LignoCelulose em solução aquosa. In: LII Congresso Brasileiro de Química, 52., 2012 Recife. Disponível em: http://www.abq.org.br/cbq/2012/.

METCALF, L.; EDDY, H. Wastewater engineering: treatment and reuse. $4^{\mathrm{a}}$ edição. New York: McGraw-Hill. 2004.

TERZYK, A.P. Further insights into the role of carbon surface functionalities in the mechanism of phenol adsorption. Journal of Colloid and Interface Science, v. 268, n. 2003, p 301-329, 2003.

ZAMORA, P.P.; KUNZ, A.; MORAES, S.G.; DURÁN, N. Novas tendências no tratamento de efluentes têxteis. Química Nova, v. 25, n. 1, p. 78-82, 2002. 